\title{
APROPIACIÓN Y DISTRACCIÓN INDEBIDAS. UNA PROPUESTA DE RECONSTRUCCIÓN UNIFICADORAMENTE DUAlista DEL ART. 470 No 1 DEL Código PENAL*
}

\author{
Juan Pablo Mañalich R.**
}

RESUMEN: El trabajo pretende sustentar una interpretación dualista del art. 470 No 1 del Código Penal, como una disposición que formula una norma de sanción que refuerza dos normas de comportamiento diferentes, cuyo quebrantamiento es respectivamente constitutivo de los delitos de apropiación indebida y de distracción indebida, entendido el primero como un delito de apropiación de cosa confiada, en tanto que el segundo como un delito de desviación, bajo abuso de confianza, de un objeto mueble de cualquier índole, resultante en un perjuicio patrimonial. Para ello se ofrecerá una clarificación de los presupuestos de tipicidad comunes a estas dos formas de comportamiento punible, para luego proceder a examinar los presupuestos típicos específicos de uno y de otro. La innovación fundamental de la reconstrucción propuesta radica en la explicación de la decisión legislativa así configurada, sobre la base de una correspondiente comprensión de la relación en que se encuentran la propiedad y el patrimonio qua respectivos objetos de protección de las dos normas de comportamiento precedentemente identificadas. A través de una defensa de la así llamada "concepción funcional del patrimonio", se intentará demostrar la necesidad de reconocer una congruencia tanto material como formal de la protección jurídico-penalmente reforzada de la propiedad y el patrimonio, cuya postulación hace posible racionalizar la decisión de tipificación dualista plasmada en el art. 470 № 1.

PALABRAS CLAVE: Teoría de las normas; apropiación y distracción indebidas; propiedad y patrimonio; perjuicio patrimonial.

Fecha de recepción: 29 de octubre de 2016.

Fecha de aceptación: 25 de enero de 2017.

** Doctor en derecho, Universidad de Bonn. Licenciado en Ciencias Jurídicas y Sociales, Universidad de Chile. Profesor titular, Departamento de Ciencias Penales, Facultad de Derecho, Universidad de Chile (Chile). Correo electrónico: jpmanalich@derecho.uchile.cl. Agradezco a una o uno de los árbitros anónimos a cuya evaluación fuera sometido el trabajo por múltiples sugerencias que han hecho posible esclarecer algunos pasajes del texto. 


\section{EMBEZZLEMENT AND UNLAWFUL DISTRACTION. A Proposal of a Unifying DUALISTIC Reconstruction of ART. 470 No 1 OF THE CHILEAN PENAL Code}

ABSTRACT: The paper seeks to ground a twofold interpretation of art. 470 No 1 of the Chilean Penal Code, as a provision which formulates a sanction norm that reinforces two different conduct norms, the transgression of which is respectively constitutive of the offenses of embezzlement and of unlawful distraction, the former being understood as an offense of appropriation of entrusted property and the latter as an offense of diversion of an entrusted object resulting in patrimonial detriment. To achieve this, a clarification of the common element of the definitions of both forms of criminal behavior will be offered, after which their respective specific elements will be examined. The fundamental innovation of the proposed reconstruction lies in the explanation of the legislative decision thus articulated, in terms of the understanding of the relation which holds between ownership and patrimony as the legal positions respectively protected by the two conduct norms under consideration. Through an argument in favor of the so called "functional conception of patrimony", the paper will attempt to demonstrate the need of recognizing both a material and formal congruence of the protection of ownership and patrimony, whose postulation enables a rationalization of the criminalization decision expressed in art. 470 No 1 .

KEYWORDS: Norm-theory; embezzlement and unlawful distraction; ownership and patrimony; patrimonial detriment.

Sumario: 1) La individuación de géneros delictivos a través de la individuación de normas de comportamiento. 2) La reconstrucción dualista de la tipificación de la apropiación y la distracción indebidas. 2.1) Las propuestas de reconstrucción monista y su inviabilidad. 2.1.1) ¿La apropiación o distracción indebida como un delito contra el patrimonio del propietario o contra un derecho personal a la entrega o devolución de la cosa confiada? 2.1.2) ¿La apropiación o distracción indebida como delito contra la propiedad? 2.2) La propuesta de reconstrucción dualista. 3) Los presupuestos de la tipicidad de la apropiación y la distracción indebidas. 3.1) Los presupuestos típicos comunes. 3.1.1) El objeto (corporal) mueble susceptible de apropiación o distracción. 3.1.2) El titulo de recepción del objeto de apropiación o distracción. 3.1.3) El perjuicio patrimonial resultante. 3.2) La especificidad de la apro- 
piación indebida. 3.3) La especificidad de la distracción indebida. 4) La congruencia de la protección de la propiedad y el patrimonio. 4.1) La propiedad como posición patrimonial. 4.2) La relación sistemática entre apropiación indebida y distracción indebida. Bibliografía citada. Jurisprudencia citada.

\section{1) LA INDIVIDUACIÓN DE GÉNEROS DELICTIVOS A TRAVÉS DE LA INDIVIDUACIÓN DE NORMAS DE COMPORTAMIENTO}

Es usual que, en la reconstrucción doctrinal de la decisión de criminalización plasmada en el art. 470 No 1 del Código Penal (en adelante, "CP"), esta sea caracterizada como una decisión de tipificación del delito de apropiación o distracción indebida. Esto significa que la interpretación más generalizada del art. 470 No 1 asume que la norma de sanción penal así formulada tipificaría un único delito. El presente trabajo persigue demostrar que tal hipótesis interpretativa es dogmáticamente insostenible, toda vez que ella es incapaz de dar cuenta de algunos datos elementales que son reconocibles ya en atención al solo tenor literal de la disposición legal. Como alternativa, aquí se defenderá la tesis de que la disposición debe ser interpretada como una en la que se plasma una decisión de criminalización dualmente configurada, en el sentido de que el art. 470 No 1 hace punibles dos formas de comportamiento delictivo heterogéneas, entre las cuales, sin embargo, cabe reconocer un determinado parentesco sistemático, cuya detección depende críticamente, a su vez, de la correcta identificación de la relación en que se encuentran los bienes jurídicos específicamente menoscabados por una y otra forma de comportamiento.

La tesis recién enunciada admite ser más precisamente formulada en el lenguaje de la teoría de las normas. En estos términos, la tesis se deja formular como sigue: la norma de sanción del art. 470 No 1 del CP refuerza dos normas de comportamiento -valga la redundancia- diferentes, cuyo quebrantamiento imputable es respectivamente constitutivo de dos géneros delictivos diferentes ${ }^{1}$. Sobre la distinción entre normas de sanción y normas de comportamiento reposa la exacta demarcación bindingiana de los conceptos de delito y de hecho punible o "crimen" (Verbrechen): mientras por "delito" cabe entender el quebrantamiento imputable de una

Para una contextualización más exhaustiva del modelo de teoría de las normas aquí favorecido como herramienta para la sistematización de la parte especial, véase Mañalich, Juan Pablo (2014) "La violación como delito contra la indemnidad sexual bajo el derecho penal chileno. Una reconstrucción desde la teoría de las normas". Ius et Praxis, ańo 20, $\mathrm{N}^{\circ} 2$, pp. 22 ss. 
norma de comportamiento, por "hecho punible" habría que entender un delito o una conjunción de delitos que satisface las ulteriores condiciones de las cuales pudiera depender su punibilidad, fijadas por la correspondiente norma de sanción y por las reglas que la complementan ${ }^{2}$. Con ello, de la individuación de la norma de comportamiento respectivamente quebrantada dependerá la identificación del correspondiente "género delictivo", cuya correspondiente extensión queda constituida por la totalidad de las instancias de quebrantamiento de esa misma norma ${ }^{3}$.

A pesar de lo extendido del reconocimiento de la distinción entre normas de sanción y normas de comportamiento, no siempre se plantea de modo suficientemente riguroso la pregunta por el método para individuar las normas de comportamiento que pueden encontrarse reforzadas por un determinado conjunto de normas de sanción. A este respecto, la respuesta menos trabajosa parecería consistir en la adopción de lo que cabría caracterizar como una tesis de correspondencia 1:1, esto es, una tesis según la cual cada norma de sanción reforzaría, exclusivamente, una determinada norma de comportamiento. La virtud de semejante respuesta radica en su simplicidad operativa. Pues la tarea de individuar cada una de las normas de comportamiento jurídico-penalmente reforzadas se volvería ciertamente más sencilla si cada norma de sanción reforzara una y nada más que una norma de comportamiento. Pero Binding demostró, con suficiente contundencia, que semejante estrategia de individuación singularizada puede resultar del todo inadecuada ${ }^{4}$. Pues es claro que hay ámbitos regulativos cuya adecuada reconstrucción puede depender de la adopción de una estrategia de individuación diversa. ¿Tendría sentido, verbigracia, asumir que el autor de un parricidio quebranta una norma distinta de la norma quebrantada por el autor de un homicidio, por la sola circunstancia de que la norma de sanción del art. 390, que tipifica el parricidio es -indiscutiblemente- divergente de la norma de sanción del

2 Binding, Karl (1922) Die Normen und ihre Übertretung I. $4^{a}$ edición. Léipzig: Félix Meiner, tomo I, pp. 194 ss.; en detalle al respecto Mañalich, Juan Pablo (2011) "El delito como injusto culpable". Revista de Derecho UACh, vol. 24, No 1, pp. 89 ss. La sustitución del término "crimen" por la expresión "hecho punible", que aquí se favorece, se orienta a evitar toda posible confusión asociada al hecho de que, legislativamente, por "crimen" se entienda un hecho punible de especial gravedad penológica, tal como sucede bajo el derecho chileno.

3 Para este concepto de "delito-género" (Gattungsdelikt), véase Binding, Karl (1902) Lebrbuch des Deutschen Strafrechts. Besonderer Teil. 2a edición. Léipzig: Wilhelm Engelmann, tomo I, pp. 5 ss.; BINDING (1922) p. 190.

$4 \quad$ En detalle Binding (1922) 188 ss. 
art. 391, que tipifica las variantes básicas y calificadas del homicidio stricto sensu? ${ }^{5}$.

No son escasos los contextos regulativos en los cuales la correcta individuación de las normas de comportamiento jurídico-penalmente reforzadas pasa justamente por no adoptar una estrategia de correspondencia 1:1. La tesis aquí defendida consiste en que justamente este es el caso tratándose de la norma de sanción expresada en el art. 470 No 1 del CP, la cual refuerza dos normas de comportamiento, una de la cuales somete al operador de la prohibición un tipo de acción consistente en la apropiación indebida de una cosa (corporal, mueble y ajena) confiada por otro, mientras la otra somete al operador de la prohibición un tipo de acción consistente en la distracción indebida de una cosa (corporal y mueble) confiada por otro. Esto equivale a afirmar que la norma de sanción en cuestión tipifica tanto un delito de apropiación indebida de cosa confiada como un delito de distracción indebida de cosa confiada. Antes de fundamentar positivamente esta última proposición será necesario, empero, demostrar la falta de plausibilidad de las propuestas interpretativas que, a diferencia de la aquí defendida, favorecen una reconstrucción monista de la decisión de tipificación plasmada en el art. 470 No 1 .

5 Que el autor de un parricidio quebrante (nada más que) la misma norma de comportamiento que el autor de un homicidio - a saber: la prohibición de matar a otro- se traduce en que no cabe reconocer un dolo específico de parricidio, diferente del dolo de homicidio, en la medida en que el dolo quede constituido por la representación de las circunstancias que fundamentan la antinormatividad -esto es, el carácter específicamente delictivo- del comportamiento que es objeto de imputación, no extendiéndose a aquellas de cuya efectividad pudiese depender, ulteriormente, la constitución del correspondiente hecho punible. $\mathrm{Al}$ respecto, y en referencia específica a la tipificación del "homicidio de ascendiente" bajo el $\$ 215$ del RStGB, véase Binding, Karl (1916) Die Normen und ihre Übertretung II. $2^{\mathrm{a}}$ edición. Léipzig: Félix Meiner, pp. 977 ss., 981 ss.,987 ss., quien al mismo tiempo observaba que el conocimiento -esto es: la representación acertada- por parte del autor, de la relación de parentesco que lo vincula con la víctima operaría como un elemento de la punibilidad, y más precisamente: en la forma de una "marca de altura" de la punibilidad del correspondiente delito (stricto sensu) de homicidio. Ello ofrece una clave para la interpretación de la cláusula "conociendo las relaciones que los ligan" del art. 390 del CP chileno, en el sentido de que el conocimiento de la relación que vincula al autor con la víctima se encuentra explícitamente reconocido como un requisito de la punibilidad (del respectivo homicidio) sub specie parricidio. Así se obtendría una fundamentación (normológica) del tradicional aserto según el cual, bajo el derecho chileno, no se dejaría construir tal cosa como un "parricidio imprudente": quien, desconociendo la respectiva relación interpersonal con relevancia bajo el art. 390, mata a otro, será ceteris paribus autor de un homicidio doloso, punible como tal bajo el art. 391 . 
2) LA RECONSTRUCCIÓN DUALISTA DE LA TIPIFICACIÓN DE LA APROPIACIÓN Y LA DISTRACCIÓN INDEBIDAS

\section{(2.1.) LAS PROPUESTAS DE RECONSTRUCCIÓN MONISTA Y SU INVIABILIDAD}

\section{(2.1.1.) ¿La apropiación o distracción indebida como un delito contra el patrimonio del propietario o contra un derecho personal a la entrega o devolución de la cosa confiada?}

\section{El art. 470 del CP dispone:}

Las penas del artículo 467 se aplicarán también:

$1^{\circ}$. A los que en perjuicio de otro se apropiaren o distrajeren dinero, efectos o cualquiera otra cosa mueble que hubieren recibido en depósito, comisión o administración, o por otro título que produzca obligación de entregarla o devolverla.

Tradicionalmente, la doctrina ha tendido a asumir una interpretación del art. 470 No 1 del CP que, en lo nuclear, se deja descomponer en dos proposiciones fundamentales, a saber: (1) que la disposición legal en cuestión tipificaría un (único) delito, que exhibiría dos variantes, respectivamente expresadas a través de las formas verbales "apropiarse" y "distraer"; y (2) que el específico contenido de ilicitud del delito así tipificado tendría que identificarse o bien (para un primer sector doctrinal) con una irrogación de perjuicio patrimonial para el propietario de la cosa confiada ${ }^{6}$, o bien (para un segundo sector doctrinal) con la vulneración del derecho personal correlativo a la obligación de entregar o devolver lo recibido 7 .

En lo tocante al primer punto, relativo a la relación en que se encontrarían las variantes entre sí, un sector doctrinal ha sostenido, más bien minoritariamente, que por "distracción" habría que entender una utilización indebida de lo recibido ${ }^{8}$, contando este planteamiento con una significativa medida de reconocimiento jurisprudencial ${ }^{9}$. Otros autores,

$6 \quad$ Etcheberry, Alfredo (1998) Derecho Penal. Parte Especial. $3^{\text {a }}$ edición. Santiago: Editorial Jurídica de Chile, tomo III, pp. 424 ss.; Garrido, Mario (2008) Derecho Penal. Parte Especial. Tomo IV. $4^{a}$ edición. Santiago: Editorial Jurídica de Chile, pp. 372 ss., p. 380.

7 Politoff, Sergio (1957) El delito de Apropiación Indebida. Santiago: Editorial Nascimento, pp. 61 ss.; Labatut, Gustavo (2005) Derecho Penal. 7a edición. Santiago: Editorial Jurídica de Chile, tomo II, p. 234.

8 ETCHEBERRY (1998) 425 ss.

9 Véanse, por ejemplo, las sentencias pronunciadas por la Corte de Apelaciones de Valparaíso. 10 de octubre del 2013. Rol № 1263-13. "Ministerio Público contra Escobar Donoso, Germán A.", especialmente en los considerandos $8^{\circ}$ y $9^{\circ}$; y por la Corte de Apelaciones de Con- 
empero, se han inclinado por una interpretación que lleva a que por "distracción" deba entenderse nada más que una forma específica que puede asumir la apropiación ${ }^{10}$, consistente en una "apropiación transitoria" de lo que ha sido recibido en depósito, comisión o administración, o bien bajo obligación de entrega o devolución.

Más allá de esta última controversia en cuanto a cómo debe entenderse la relación entre las dos variantes típicas, la propuesta de interpretación del art. 470 No 1 aquí considerada se distingue por postular que la norma de sanción en cuestión tipificaría nada más que un delito, cuyo injusto, a su vez, siempre se correspondería con el menoscabo de uno y el mismo bien jurídico. Ella puede ser caracterizada como una propuesta de reconstrucción monista de la decisión de tipificación plasmada en la disposición legal.

Sistemáticamente, el punto de apoyo más importante para esta interpretación consiste en la posición del art. 470 No 1 en el contexto del Título IX del Libro II del CP, a saber: bajo el Párrafo 8, cuyo epígrafe reza "Estafa y otros engaños". Si bien este epígrafe no es idiomáticamente afortunado, es pacífico que un conjunto significativo de los delitos tipificados bajo este mismo párrafo se dejan caracterizar como delitos de "defraudación" (lato sensu), lo cual significa: como delitos de irrogación de perjuicio patrimonial. Y esta última consideración revela, adicionalmente, cuál es el otro dato regulativo, plasmado en el tenor literal del art. 470 No 1 , que asimismo sirve de sustento a la interpretación favorecida por el sector doctrinal que identifica el contenido de injusto de la apropiación o distracción indebida con una irrogación de perjuicio patrimonial al propietario de la cosa confiada, a saber: la exigencia de que la apropiación o distracción tenga lugar, justamente, "en perjuicio de otro"11.

Pero el problema capital que enfrenta semejante interpretación, bajo cualquiera de las dos posibles caracterizaciones de la relación en que se encontrarían las variantes típicas de apropiación y distracción, radica precisamente en su inverosimilitud ante otro dato regulativo, igualmente insoslayable, a saber: que el art. 470 No 1 tipifica un delito que a lo menos bajo una de sus variantes tiene que soportar ser caracterizado como un delito de apropiación. Ahora bien, el problema no está dado por la circunstancia de que la norma vincule la caracterización del hecho como una apropiación de lo recibido en depósito, comisión o administración, o bajo obligación de entrega o devolución, por un lado, con la exigencia de

cepción. 23 de julio del 2010. Rol N²73-2010. "Ministerio Público contra Ulloa Pino, Leonardo Alex", especialmente en el considerando 7o.

$10 \quad$ Politoff (1957) 61 ss., 230 ss.; Labatut (2005) 235; Garrido (2008) 377 ss.

11 Garrido (2008) 380. 
que de ello resulte un perjuicio para otra persona, por otro. Pues nada inconsistente hay en que la regulación legal pueda condicionar la relevancia típica de la apropiación de una cosa ajena a una exigencia de irrogación de perjuicio a otro. Esto, en el entendido de que por "perjuicio" ha de entenderse aquí un perjuicio de significación patrimonial, lo cual vale con total independencia de cómo llegue a ser respondida la difícil pregunta acerca de cómo ha de definirse, para tal efecto, la noción de patrimonio ${ }^{12}$. Antes bien, el problema estriba precisamente en el hecho de que la ley recurra al concepto de apropiación a la vez que incluye una referencia al dinero en la especificación del posible objeto de apropiación o distracción.

La dificultad se suscita porque, salvo en aquellos casos en los cuales el dinero es recibido como cosa específica, quien recibe dinero se hace eo ipso dueño del mismo, en conformidad con el régimen plasmado en el Código Civil. Como es sabido, ello se funda en la radical fungibilidad que exhibe el dinero, que lo convierte en una cosa singularísima desde el punto de vista del estatuto jurídico que es propio de las cosas: el dinero es una cosa que sirve como medida de valor de cualquiera cosa comerciable, que es justamente lo que lo convierte en el instrumento de cambio por antonomasia ${ }^{13}$.

Luego, la radical fungibilidad que es característica del dinero se expresa en que, salvo en los casos en los cuales el dinero es recibido bajo especificación, cada vez que una persona recibe dinero, por cualquier título, ella se convierte en propietaria del dinero recibido. Con ello, la eventual obligación de devolver o entregar solo puede consistir, en tal caso, en una obligación de entregar o devolver una suma de dinero equivalente ${ }^{14}$. Y la consecuencia que de ello se sigue es manifiesta: si quien recibe dinero no

12 Véanse infra, 3.1 .3 y 4.

13 Tomasello, Leslie (1994) Las obligaciones de dinero: régimen de reajuste e intereses. $2^{\text {a }}$ edición. Valparaíso: Edeval, pp. 16 ss.

14 Que tal obligación de dinero deba ser caracterizada, stricto sensu, como una "obligación de género", como tiende a asumirse por la doctrina civil chilena -véase solo Fueyo, Fernando (1958) Derecho Civil IV. De las obligaciones. Valparaíso: Imprenta y Litografía Universo, vol. 1, pp. 163 ss.; Abeliuk, René (1993) Las Obligaciones. $3^{a}$ edición. Santiago: Editorial Jurídica de Chile, tomo I, p. 291.; Tomasello (1994) 23 ss.-, es algo en lo que no es necesario entrar aquí. Para una muy convincente refutación de semejante caracterización, en inmediata referencia al derecho privado alemán, véase Larenz, Karl (1987) Lebrbuch des Schuldrechts. $14^{a}$ edición. Múnich: Beck, tomo I, pp. 167 ss., quien observa que el deudor de una obligación de dinero tiene que poner a disposición del acreedor una determinada suma de dinero (en el sentido de una "obligación de suma"), y no individuos "de calidad media" del "género respectivo", ańadiendo que la noción misma de un billete "de calidad media" carece de todo sentido desde este punto de vista. Nada de esto obsta, empero, a que tenga sentido diferenciar las situaciones en las cuales una suma de dinero es recibida como cosa específica, por un lado, o como cosa genérica, por otro, sin que ello prejuzgue el carácter de la obligación eventualmente contraída por quien lo recibe de una u otra forma. 
especificado se hace eo ipso dueño del mismo, entonces por definición estará excluida la posibilidad de que esa misma persona se apropie del dinero en cuestión ${ }^{15}$, precisamente porque no es conceptualmente posible una apropiación de cosa propia ${ }^{16}$.

Luego, la objeción fundamental que cabe esgrimir en contra de la interpretación hasta aquí considerada es la siguiente: ella no logra ofrecer una lectura plausible de una disposición legal que tipifica una forma de comportamiento que, al menos en una de sus variantes, tiene que satisfacer una descripción construida sobre la noción de apropiación, noción que parece ser más bien congruente con la tipificación de un delito contra la propiedad, y no de un delito contra el patrimonio o contra un derecho personal de significación patrimonial. A favor de esta hipótesis habla una consideración sistemática tan elemental como elocuente: el otro contexto en el cual la ley recurre, característicamente, a la noción de apropiación es el de la tipificación, construida a partir de las definiciones plasmadas en el art. 432 del CP, de los delitos de hurto, robo con fuerza en las cosas, robo por sorpresa y robo con violencia o intimidación en las personas, que inequívocamente cuentan como delitos contra la propiedad.

\section{(2.1.2.) ¿La apropiación o distracción indebida como delito contra la propiedad?}

En efecto, y justamente en el marco de una muy fundada crítica de la propuesta interpretativa hasta aquí considerada, Soto Piñeiro ha ofrecido una fundamentación de una interpretación del art. 470 No 1 que resulta en la tesis de que el delito allí tipificado exhibiría el carácter de un delito contra la propiedad, precisamente en la forma de un delito de apropiación de cosa recibida bajo un título fundante de una relación de confianza especial ${ }^{17}$. Para ello, Soto afirma que la noción de distracción representaría nada más que una especificación de la noción de apropiación, de manera tal que por "distracción" habría que entender una forma de apropiación que se distingue por consistir en el uso indebido de la cosa recibida, en la medida en que en ese uso indebido sea reconocible una

El desconocimiento del problema también es característico de la elaboración doctrinal de la tipificación de la apropiación indebida bajo el CP español de 1944; véase Cuello Calón, Eugenio (1957) Derecho Penal. 10a edición. Barcelona: Bosch, tomo II, pp. 888 ss.

16 Para una muestra de la falta de advertencia del problema en el contexto jurisprudencial, véase por ejemplo la sentencia pronunciada por la Corte de Apelaciones de San Miguel. 30 de abril del 2009. Rol N 110-2009. "Hernández Arata, César Marcelo con Contreras Castillo, Ana María", en sus considerandos $10^{\circ}$ y $11^{\circ}$.

17 Soto, Miguel (1994) Apropiación indebida. Santiago: ConoSur, pp. 29 ss. 
arrogación del contenido fáctico de poder que es inherente a la posición de propietario, respecto de esa misma cosa ${ }^{18}$.

Para sustentar esta tesis, Soto se ve forzado a favorecer una interpretación del art. 470 No 1 bajo la cual, en cuanto objeto del comportamiento punible, el "dinero" solo podría consistir en dinero que el potencial autor ha recibido como especie o cuerpo cierto ${ }^{19}$, precisamente porque solo en tal caso quien recibe el dinero no se hace dueño del mismo, de manera tal que el dinero en cuestión pueda ser objeto de una apropiación antijurídica por parte de quien lo ha recibido. La tesis de Soto resulta internamente consistente, pero a un precio que la hace, al mismo tiempo, insostenible. Es inequívoco, por un lado, que un dato regulativo habla decisivamente a su favor, a saber: que la disposición legal en efecto haga uso de la noción de apropiación para la descripción del comportamiento punible. Sin embargo, tanto la posición sistemática de la misma disposición, al interior del Título IX del Libro II del CP, como la circunstancia de que la tipificación en ella plasmada incorpore una exigencia de perjuicio para otro, y sobre todo que la referencia regulativa al dinero no sugiera en modo alguno una restricción al dinero recibido como cosa específica, hablan decisivamente en contra de la viabilidad de semejante propuesta interpretativa.

\section{(2.2.) LA PROPUESTA DE RECONSTRUCCIÓN DUALISTA}

El hallazgo de la inviabilidad de cada una de las dos propuestas interpretativas que asumen una reconstrucción monista de la tipificación plasmada en el art. 470 No 1 del CP sirve de premisa capital para la elaboración de una reconstrucción dualista, tal como ello viene siendo sugerido por un creciente sector de la doctrina ${ }^{20}$. Desde luego, existen divergencias importantes entre las variantes de reconstrucción dualista que se conocen en la bibliografía especializada, pero es común a todas ellas un abandono de la premisa de que lo tipificado en esa misma disposición legal sería una forma de comportamiento delictivo homogénea, cuyo específico conte-

\footnotetext{
18 Sото (1994) 54 ss.

19 Verbigracia, "en arca cerrada [...] o con otras precauciones que hagan imposible tomarlo sin fractura", según la fórmula con la que el art. 2221 del Código Civil ejemplifica los presupuestos de existencia de un depósito irregular.

20 Véase Bascuñán, Antonio (2004) "Delitos contra intereses instrumentales". Revista de Derecho de la Universidad Adolfo Ibáñez, Nº 1, pp. 335 ss.; Hernández, Héctor (2005) "La administración desleal en el derecho penal chileno". Revista de Derecho de la Pontificia Universidad Católica de Valparaíso, vol. XXVI, pp. 210 ss., 228 ss.; De LA Fuente, Felipe (2005) "Delitos contra bienes instrumentales". Revista de Derecho de la Universidad Adolfo Ibánéz, N 2, pp. 597 ss., 602 ss.
} 
nido de ilicitud se correspondería con el menoscabo de uno y el mismo bien jurídico.

La mejor formulación de tal tesis dualista se deja presentar, según ya se anticipara, como sigue: en el art. 470 No 1 se encuentran tipificadas dos formas de comportamiento delictivo heterogéneas ${ }^{21}$, que admiten ser designadas a través de las denominaciones "apropiación indebida" y "distracción indebida". La primera exhibe el carácter de un delito de apropiación de cosa mueble con abuso de confianza -esto es, de apropiación "de cosa confiada"-, cuya tipicidad en todo caso depende del condicionamiento de un resultado de perjuicio patrimonial (para el propietario o para un tercero) que debe ser correlativo a la obtención del poder de disposición sobre la cosa por parte de quien se la apropia ${ }^{22}$. Por su parte, la distracción indebida tiene el carácter de un delito de irrogación de perjuicio patrimonial mediante abuso de confianza, que se configura a través de una "desviación" o utilización indebida del objeto (mueble) recibido, lo cual ha de comprometer o bien la realización de la finalidad para la cual ese objeto fuera entregado, o bien la satisfacción del derecho personal (de otro) correlativo a la obligación de entregar o devolver la cosa en cuestión $^{23}$. Es justamente en estos términos que se vuelve posible postular una conexión entre la caracterización de la distracción indebida como un delito de "administración desleal" 24 , por un lado, con su caracterización como un delito de "insolvencia punible" 25 , por otro. Pues allí donde la cosa ha sido recibida bajo obligación de entregarla o devolverla, el abuso de confianza implicado en su distracción ha de condicionar la imposibilidad del potencial autor de cumplir esa misma obligación de entrega o devolución, en circunstancias de que es en la falta de satisfacción del derecho personal correlativo a esa obligación donde debe radicar el perjuicio patrimonial resultante de la distracción.

Y no un delito "de doble naturaleza”; véase empero Bascuñán (2004) 338 ss.

Se trata, en tal medida, de un delito del todo equivalente a lo que el derecho alemán conoce como Veruntreuung, que es una variante calificada, por abuso de confianza, del delito de (simple) apropiación de cosa ajena (Unterschlagung), tipificada en el apartado $2^{\circ}$ del $\$ 246$ del CP alemán. Véase por todos, Kindhäuser en Kindhäuser, Urs; Neumann, Ulfrid; PAEffGen, Hans-Ullrich (2013). Nomos Kommentar. Strafgesetzbuch. 4a Edición. Baden-Baden: Nomos, tomo III, $\$ 246$, núm. marg. 40. Acerca de la conexión entre la Veruntreuung y el "hurto impropio" por abuso de confianza, véase ya Carrara, Francesco (1966) Programa de Derecho Criminal. Parte Especial. 2a edición. Bogotá: Temis, vol. IV, pp. 362 ss.

23 Véase Hernández (2005) 229 ss., quien acertadamente tematiza el carácter de delito de "insolvencia punible" singularizada (desde el punto de vista del respectivo vínculo obligacional) que es predicable de la distracción indebida en cuanto delito de perjuicio patrimonial. Véase Bascuñán (2004) 339 ss.; De la Fuente (2005) 602 ss. 
En lo que sigue se ofrecerá una clarificación de los presupuestos de tipicidad comunes a las dos formas de comportamiento punibles que, de acuerdo con la propuesta recién esbozada, se encuentran conjuntamente tipificadas en el art. 470 No 1 del CP, para luego proceder a examinar los presupuestos típicos específicos de una y de otra.

\section{3) LOS PRESUPUESTOS DE LA TIPICIDAD DE LA APROPIACIÓN Y LA DISTRACCIÓN INDEBIDAS}

\section{(3.1.) LOS PRESUPUESTOS TÍPICOS COMUNES}

\section{(3.1.1.) El objeto (corporal) mueble susceptible de apropiación o distracción}

Los delitos de apropiación indebida y distracción indebida de cosa confiada comparten, como primer presupuesto típico común, la exigencia de que el objeto del hecho respectivo esté constituido por "dinero, efectos o cualquiera otra cosa mueble". Cualquier objeto corporal mueble de naturaleza comerciable puede exhibir, entonces, relevancia típica a uno u otro título. La única salvedad, a este respecto, concierne al dinero y en general a cualquiera cosa mueble de naturaleza fungible, cuando es recibida como cosa genérica. Pues en tal caso, y con independencia de la especificidad del título por el cual se la recibe, la cosa pasa a ser eo ipso de propiedad de quien la ha recibido ${ }^{26}$, justamente porque en razón de su objeto (constituido por dinero en cuanto cosa genérica) el título en cuestión será traslaticio de dominio.

La única clarificación ulterior que se impone en el presente contexto concierne a qué ha de entenderse por "efectos". En general, se entiende aquí por tales todos aquellos documentos susceptibles de estimación pe-

26 En contra de lo sugerido por Hernández (2005) 213 ss., los "casos en los que no se entrega la custodia del dinero sino solo la aprehensión física transitoria y controlada del mismo" no representan una "excepción adicional" (cursivas añadidas) a la de la entrega del dinero bajo especificación frente a la "regla general" de que el mismo sea entregado como cosa genérica. Pues los casos a los que alude Hernández son casos en que el dinero es entregado o bien bajo lo que cabría llamar una "especificación ostensiva", en el sentido de que el dinero en cuestión sigue estando especificado por la circunstancia de que la referencia individualizada a las monedas o los billetes respectivos es contextualmente posible a través del uso de una expresión lingüística que funcione como un pronombre demostrativo, o bien bajo lo que cabría llamar una "especificación mecánica", allí donde se trata de la operación de sistemas de tratamiento físico de dinero. 
cuniaria y que expresan un valor negociable, y que en jerga más moderna son habitualmente denominados "títulos-valores" 27.

\section{(3.1.2.) El título de recepción del objeto de apropiación o distracción}

El segundo presupuesto común de la tipicidad de la apropiación y distracción indebidas está constituido por la exigencia de que el objeto del hecho potencialmente constitutivo de apropiación o distracción haya sido recibido o bien en depósito, comisión o administración, o bien por algún título que genere una obligación de entregar o devolver lo recibido.

La doctrina ha tendido a asumir, unánimemente, una interpretación del art. 470 No 1 del CP según la cual en la cláusula "por otro título que produzca obligación de entregarla o devolverla" se expresaría una exigencia típica general, la cual se encontraría meramente especificada, por vía de simple ejemplificación, en la cláusula inmediatamente antecedente, que alude al depósito, la comisión o la administración como títulos bajo los cuales el objeto de apropiación o distracción ha podido ser recibido ${ }^{28}$. Esa interpretación, por más extendida que se encuentre, es abiertamente problemática. Pues ella descansa en una lectura de la cláusula genérica (mas no "general"), ya reproducida, que trastoca su tenor.

Para que pudiera sostenerse que la exigencia de que el objeto haya sido recibido "en depósito, comisión o administración" no constituye más que una ejemplificación de la exigencia de que el objeto en cuestión haya sido recibido bajo obligación de entrega o devolución, la cláusula en cuestión debería no rezar como de hecho reza ("por otro título..."), sino más bien como sigue: "por cualquier otro título que produzca una obligación de entregarla o devolverla" ${ }^{29}$. Pues solo entonces sería posible afirmar que, en el contexto de la disposición legal, el depósito, la comisión o la administración también serían títulos necesariamente generativos de una obligación de entregar o devolver lo recibido. Sin embargo, es manifiestamente falso que el depósito, la comisión o la administración sean títulos que siempre y en todo caso fundamentan una obligación de entrega o devolución de un objeto recibido en razón de ese mismo título. Antes bien,

Etcheberry (1998) 426 ss.; Garrido (2008) 379. Sobre el concepto de título-valor, véase Sandoval, Ricardo (2015) Derecho Comercial. Santiago: Editorial Jurídica de Chile, tomo II, pp. 17 ss.

28 Politoff (1957) 139; Sото (1994) 41 ss., 49 ss.

29 Semejante reformulación aparece en GARRIDo (2008) 375, quien aparentemente no advierte la tergiversación, así efectuada, del tenor de la disposición legal; en iguales términos Politoff, Sergio; MATUS Jean; Ramírez, María (2004) Lecciones de Derecho Penal Chileno. Parte Especial. 2a edición. Santiago: Editorial Jurídica de Chile, p. 457. 
y dependiendo de cuál sea la naturaleza del objeto mueble recibido y de cuál sea la finalidad perseguida por la persona de quien se recibe el objeto, habrá casos en los cuales tendrá que negarse que el objeto haya sido recibido bajo obligación de entrega o devolución, lo cual dejará intacta la punibilidad de su eventual apropiación o distracción ${ }^{30}$.

Así, por ejemplo, quien como mandatario o comisionista ha recibido una cosa, como especie o cuerpo cierto, para venderla, precisamente no contraerá al recibirla una obligación de entregarla o devolverla, sino una obligación (de hacer) consistente en (lograr) venderla ${ }^{31}$. En tal caso, la apropiación o la distracción de la cosa para cuya venta la persona del mandatario ha sido comisionada resultará respectivamente punible bajo el art. 470 No 1 del CP, precisamente por haber sido recibida "en comisión", y no bajo una obligación de entregarla o devolverla. Algo similar sucedería tratándose de la recepción de una cosa consumible a ser exclusivamente usada en la gestión o administración de un negocio ajeno. Siendo claro que, en tal caso, el potencial autor no habrá recibido la cosa bajo obligación de entregarla o devolverla, de él sí habrá que decir que la ha recibido "en administración", lo cual bastará para conferir relevancia típica a su eventual apropiación o distracción por parte de quien así la ha recibido. Finalmente, considérese el caso de quien recibe dinero no especificado en depósito, que en tal medida contará como "irregular": si bien el depositario se hará eo ipso dueño del dinero recibido, lo cual excluye tanto la posibilidad de una apropiación del mismo dinero por su parte como la generación, para él, de una obligación de entregar o devolver los billetes o las monedas en que consiste el dinero efectivamente recibido, una desviación de la suma pecuniaria en cuestión, que volviera imposible su posterior cumplimiento de la obligación (prevista en el art. 2221 del Código Civil) de "restituir otro tanto en la misma moneda", podría exhibir relevancia típica a título de distracción indebida.

30 El punto fue claramente enfatizado por CARRARA (1966) 364, quien explicando su propia definición del delito de "abuso de confianza" observaba: "Se dice [que la cosa se ha recibido] para un uso determinado, no para conservarla y devolverla al dueño; por lo tanto, recae verdadero abuso de confianza sobre la cosa que se le da a otro para que la venda por cuenta del dueño, como en cualquier otro caso que no traiga consigo la obligación de devolver, por ejemplo, si un individuo vende el estiércol que le entregué para emplearlo en las plantas de mi huerto".

31 Ciertamente, cabría sostener que el comisionista sí recibe la cosa bajo un título que conlleva la obligación de restituirla al mandante, en caso de que no logre venderla. Pero tal obligación se encontraría, al momento en que la cosa es recibida por el comisionista, sometida a la condición suspensiva de que ella no llegue a ser vendida. Y una obligación sometida a una condición suspensiva es una obligación que recién "nace" -esto es, se genera- con el (eventual) cumplimiento de la respectiva condición. Véase solo Abeliuk (1993) 385, 404 ss. 
De ahí que, de acuerdo con la tesis aquí defendida, no sea en la aptitud para generar una obligación de entregar o devolver lo recibido que radica el criterio de relevancia típica del título respectivo. Pues la relevancia típica de un depósito, una comisión o una administración, en cuanto títulos de recepción de dinero, efectos o alguna cosa mueble cualquiera, no depende de la eventual generación de semejante obligación. Pero ello no obsta a que, en todo caso, el objeto de apropiación o distracción tenga que haber sido recibido por un título fundante de un vínculo de confianza especial en lo tocante a su conservación o utilización, según correspon$\mathrm{da}^{32}$. Y ese vínculo quedará ulteriormente especificado según cuál sea la naturaleza del título. Tratándose de una comisión o una administración, correspondiéndose ambos títulos con formas que puede exhibir un mandato $^{33}$, el vínculo de confianza especial asume la forma de un vínculo propiamente fiduciario ${ }^{34}$, que se traduce en que el comisionista o administrador queda sometido a una obligación de lealtad en la gestión del asunto o negocio ajeno que involucra el objeto (mueble) así recibido ${ }^{35}$; tratándose de un depósito, el vínculo de confianza especial se encuentra referido a la custodia y conservación de aquello que se recibe en depósito $^{36}$. En los demás casos, el respectivo vínculo de confianza especial se expresará en la obligación, contraída por quien ha recibido una cosa mueble, de entregar o devolver precisamente esa misma cosa, en cuanto cosa específica. Como títulos fundantes de semejante obligación pueden venir en consideración, entre otros y característicamente, el fideicomiso (desde el punto de vista del propietario fiduciario), el usufructo (desde el punto de vista del usufructuario), el comodato (desde el punto de vista del comodatario), el arrendamiento (desde el punto de vista del arrendatario) y la prenda (regular) con desplazamiento (desde el punto de vista del acreedor prendario $)^{37}$.

32 Fundamental al respecto Soler, Sebastián (1987) Derecho Penal Argentino. $4^{a}$ edición. Tea: Buenos Aires, tomo IV, pp. 423 ss., con la precisión de que la noción aquí relevante es una de "confianza jurídica", y no de "confianza personal".

33 Véase Politoff (1957) 167.

34 Para una caracterización funcional de las relaciones fiduciarias, véase PARDow, Diego (2006) "Potestades de administración y deberes fiduciarios. Una aproximación analítica a los deberes asociados a la administración de un patrimonio ajeno". En Corral, Hernán y Rodríguez, María Sara (coordinadores): Estudios de Derecho Civil II. Santiago: LexisNexis, pp. 89 ss.

35 Véase Labatut (2005) 234 ss., quien sostiene que el art. 470 No 1 contendría una exigencia general de tenencia fiduciaria como presupuesto típico.

36 Nótese que el contrato de depósito se encuentra legalmente definido (en el art. 2.211 del Código Civil) como uno por el cual "se confía una cosa corporal a una persona que se encarga de guardarla y restituirla en especie”.

37 La exclusión de la prenda irregular resulta determinada por la circunstancia de que, recayendo sobre cosa fungible, el correspondiente contrato de garantía no fundamenta una obliga- 


\section{(3.1.3.) El perjuicio patrimonial resultante}

El tercer presupuesto común de la tipicidad de las dos formas de comportamiento delictivo previstas en el art. 470 No 1 del CP está constituido por la exigencia de irrogación de perjuicio (patrimonial) a alguna otra persona. De cómo sea más precisamente entendida esta exigencia depende, ahora bien, cuál sea la relación sistemática que deba reconocerse entre los delitos de apropiación y de distracción indebidas.

La dificultad está dada por la circunstancia de que, según ya se sostuviera, mientras la distracción indebida tiene que ser entendida como un delito contra el patrimonio ajeno, la apropiación indebida ha de caracterizarse como un delito contra la propiedad. Y esto podría favorecer la conclusión de que solo tratándose de una distracción indebida tendría sentido identificar la irrogación de perjuicio a otra persona como un elemento propiamente constitutivo del específico contenido de ilicitud del hecho, en tanto que, tratándose de una apropiación indebida, esa exigencia solo podría desempeñar la función de una condición objetiva de punibilidad, puramente limitativa de la relevancia jurídico-penal del hecho constitutivo de un atentado contra la propiedad de otro ${ }^{38}$. El problema está en la premisa sobre la cual se asienta, implícitamente, el razonamiento precedente. La premisa consiste en la hipótesis de que, bajo la tipificación de un delito contra la propiedad, sería anómalo condicionar la tipicidad del hecho (constitutivo del respectivo delito consumado) a la exigencia de que de él resulte un perjuicio de naturaleza patrimonial para otro. Mas esta hipótesis se deja poner en cuestión por, a lo menos, dos vías diferentes.

Por un lado, es perfectamente posible que, según como sean definidas más precisamente las nociones de patrimonio y-consiguientementede perjuicio patrimonial, la exigencia de que una apropiación indebida de cosa confiada resulte en una irrogación de perjuicio patrimonial para otra persona se deje entender como internamente conectada con un menoscabo para la propiedad ajena en cuanto bien jurídico específicamente lesionado por el hecho punible así configurado. Ello será el caso tratándose de cualquier concepción del patrimonio bajo la cual todo menoscabo para la propiedad de otro represente eo ipso un menoscabo para su patrimonio.

ción de entregar o devolver la cosa específicamente recibida para el acreedor prendario, en circunstancias de que la prenda no está prevista -a diferencia del depósito, la comisión y la administración- como un título per se suficiente para conferir relevancia típica, bajo el art. 470 No 1, al objeto pignoraticio. Al respecto, acertadamente, ya Politoff (1957) 152 ss. 
Tal es el estatus de la así llamada "concepción jurídica del patrimonio", tempranamente articulada por Binding ${ }^{39}$, pero también de la así llamada "concepción funcional del patrimonio", contemporáneamente defendida por Kindhäuser ${ }^{40}$.

Bajo cualquiera de estas concepciones, la arrogación del poder fáctico de disposición sobre la cosa recibida en el marco de un vínculo de confianza especial por parte de quien -en tal medida- se la apropia conlleva, ceteris paribus, un menoscabo para una posición de significación patrimonial para la persona que ostenta la posición formal de propietario sobre esa misma cosa. Por ello, la exigencia explícitamente expresada en el art. $470 \mathrm{~N}^{\circ} 1$ del CP en cuanto a que de la apropiación de la cosa confiada resulte un perjuicio para otra persona, que bajo tal interpretación solo puede ser el propietario, debe ser entendida como desempeńando la función negativa de excluir la relevancia típica de tal apropiación en aquellos casos en los cuales quien se apropia de la cosa satisface -aun cuando "arbitrariamente", en la forma de un ejercicio de autotutela- un derecho personal correlativo a una obligación de dar, que recae en la persona del propietario respecto de esa misma cosa en cuanto especie o cuerpo cierto, siempre que la obligación en cuestión sea actualmente exigible. Así entendida la exigencia de perjuicio, la atipicidad, a título de apropiación indebida, del ejercicio autotutela consistente en la retención de la cosa por parte de la persona a quien ella es específicamente debida opera como el equivalente funcional de la atipicidad, a título de hurto, del apoderamiento de la cosa por parte del acreedor que por esa vía se "hace pago" con ella, que es posible reconstruir con apoyo en el art. 494 No 20 del $\mathrm{CP}$, que tipifica la falta de realización arbitraria del propio derecho ${ }^{41}$.

Pero por otro lado, y en la medida en que se asuma una definición del concepto de patrimonio divergente de las concepciones recién mencionadas, tal como paradigmáticamente ocurre tratándose tanto de la así llamada "concepción económica" como de la así llamada "concepción jurídico-económica”, todavía será posible conferir sentido a la exigencia de irrogación de perjuicio para otro a resultas de la apropiación de la cosa confiada por quien la ha recibido por algún título típicamente rele-

\footnotetext{
39 BINDING (1902) 237 ss.

40 Kindhäuser, Urs (2002) Estudios de derecho penal patrimonial. Lima: Grijley, pp. 34 ss., 125 ss.; KindhäUser, Urs (2011) "Concepto de patrimonio y perjuicio patrimonial. Sobre los defectos congénitos de la doctrina económica del perjuicio en el derecho penal”, Anuario de Derecho Penal Económico, vol. 1, pp. 51 ss., 57 ss.; Mañalich, Juan Pablo (2009) Autotutela del acreedor y protección penal del deudor. Santiago: Ediciones Jurídicas de Santiago, pp. 116 ss.

41 Véase en detalle Mañalich (2009) 33 ss.
} 
vante $^{42}$. Pues no hay obstáculo alguno a que la regulación de los delitos contra la propiedad pueda conferir relevancia a un eventual menoscabo patrimonial, ya sea como un criterio de determinación complementaria del específico injusto de un delito de apropiación, ya sea como un criterio de cuantificación de este ${ }^{43}$. Bajo semejante interpretación de la exigencia de irrogación de perjuicio para otro, en cualquier caso, la misma tendría que entenderse estrictamente referida a la posición del propietario de la cosa indebidamente apropiada, de manera tal que la exigencia opere excluyendo la relevancia típica de aquellas instancias de apropiación de una cosa confiada por otro que no conlleven una merma patrimonialmente relevante para este. Tal sería el caso, paradigmáticamente, tratándose de la apropiación de una cosa que solo exhibe valor de afección para su propietario, mas no valor pecuniario.

Ciertamente, cual sea la definición del concepto jurídico-patrimonial que se defienda determinará, asimismo, en qué haya de consistir el resultado de perjuicio patrimonial de cuya irrogación depende la tipicidad de una distracción indebida como segunda forma de comportamiento punible bajo el art. $470 \mathrm{No}^{1}$ del $\mathrm{CP}^{44}$. La particularidad de la conexión entre tal resultado de perjuicio y la fisonomía del hecho constitutivo de distracción del dinero, los efectos o la cosa específicamente confiada, queda determinada, en todo caso, por la circunstancia de que el perjuicio en cuestión debe quedar asociado a la falta de realización de la finalidad en razón de la cual tuvo lugar la recepción del dinero, los efectos o la cosa, en la medida en que el título para su recepción haya consistido, paradigmáticamente, en alguna forma de mandato, o bien a la falta de satisfacción del derecho personal correlativo a la obligación de entregar o devolver la cosa recibida como especie o cuerpo cierto, según corresponda.

\section{(3.2.) LA ESPECIFICIDAD DE LA APROPIACIÓN INDEBIDA}

Más allá de los presupuestos comunes que definen el ámbito típico compartido por la apropiación y la distracción indebidas, los específicos

\footnotetext{
42 Véase Hernández, Héctor (2009) "Frustración de fines y perjuicio patrimonial en el derecho penal chileno". Derecho Penal Contemporáneo, No 29, pp. 57 ss., 85 ss., argumentando a favor de una concepción puramente económica. Para una defensa de la concepción jurídicoeconómica, Schlack, Andrés (2008) "El concepto de patrimonio y su contenido en el delito de estafa". Revista Chilena de Derecho, vol. 35, N 2, pp. 278 ss., 285 ss.

43 Esto último sucede, en efecto, bajo la tipificación de las diferentes variantes de hurto, en la medida en que la regulación atiende al valor pecuniario del objeto de la respectiva apropiación (mediante sustracción) para cuantificar su gravedad relativa para los efectos de la fijación de los marcos de penalidad respectivamente aplicables. 
presupuestos de la tipicidad de una apropiación indebida quedan determinados, valga la redundancia, por su carácter de delito de apropiación. Para que la recepción de una cosa por un título constitutivo de un vínculo de confianza especial ponga a quien la recibe en situación de poder apropiársela antijurídicamente, es necesario, en primerísimo lugar, que la cosa recibida conserve su estatus de ajena a través de su recepción. No está de más advertir que el hecho de que el art. 470 No 1 del CP no haga explícita la exigencia de que el objeto de apropiación indebida exhiba el estatus de una cosa ajena (desde el punto de vista del autor) es algo que se deja explicar perfectamente a partir de la propuesta de reconstrucción dualista aquí favorecida: la exigencia de ajenidad de la cosa confiada está implicada por la descripción de esta primera forma de comportamiento delictivo a través de la noción de apropiación, en circunstancias de que el objeto de una distracción indebida no necesita exhibir el estatus de una cosa ajena.

El carácter de ajena de la cosa confiada resultará excluido si ella es de naturaleza fungible y es recibida como cosa genérica. Pues en tal caso, según ya se anticipara, quien recibe la cosa se hace eo ipso dueńo de la misma, quedando solo obligado, en su caso, a devolver "otro tanto" del mismo género. Tal como ya se ha advertido, esto es de inmediata importancia de cara a la recepción de dinero por algún título típicamente relevante: en tanto el dinero en cuestión no sea recibido como cosa específica, el mismo no podrá contar como objeto de una apropiación por parte de quien lo ha recibido (subsistiendo, desde luego, la posibilidad de una distracción indebida a su respecto).

Nótese que, en contra de lo sostenido por Politoff a propósito del depósito irregular como posible título típicamente relevante, lo anterior también vale en caso de que al depositario se prohíba expresamente hacer uso del dinero depositado ${ }^{45}$. Pues aun en caso de que el depositario no restituya una suma de dinero equivalente a la recibida, el tipo de la apropiación indebida no se verá realizado por su comportamiento, justamente porque el depósito de dinero no especificado opera como un título traslaticio de dominio, en exclusiva atención a su carácter de cosa (radicalmente) fungible ${ }^{46}$.

Por otra parte, es necesario determinar la noción misma de apropiación en cuanto marca del núcleo típico. Por "apropiación" ha de entenderse la arrogación del poder fáctico de disposición (lato sensu) que es correlativo a la posición formal de propietario, lo cual supone un desconocimiento "práctico" de la propiedad ajena sobre la cosa. Esto significa que

\footnotetext{
45 Politoff (1957) 157 ss.

46 Acertadamente Hernández (2005) 213 ss., 216 ss.
} 
la apropiación de la cosa confiada ha de consistir en una manifestación objetivada de una pretensión rem sibi habendi en relación con la cosa ${ }^{47}$. En tal medida, se trata de exactamente la misma noción que es propia de la tipificación de los delitos de apropiación mediante sustracción, cuya forma básica está constituida por el hurto. La diferencia específica entre la estructura típica del hurto y la de la apropiación indebida, desde este punto de vista, radica en que, en cuanto delito de sustracción, el hurto consiste en la apropiación de una cosa mueble ajena a través de la ruptura de la custodia que otro tiene sobre la cosa, mientras la apropiación indebida consiste en la apropiación de una cosa detentada por el autor, quien precisamente ha de haberla recibido en el marco de una relación de confianza especial.

La apropiación de la cosa así recibida puede manifestarse de múltiples formas ${ }^{48}$ : tanto su uso y goce como su traspaso a un tercero, y así también su destrucción, pueden ser indicativos de la pretensión de posicionarse a su respecto como señor y dueño ${ }^{49}$. Como es obvio, la apropiación también puede configurarse a través de la retención de la cosa recibida frente a la exigencia de su entrega o devolución por parte de la persona a quien el título respectivo confiere ese derecho ${ }^{50}$.

\section{(3.3.) LA ESPECIFICIDAD DE LA DISTRACCIÓN INDEBIDA}

Según ya se anticipara, el delito de distracción indebida tiene que ser entendido como un delito de irrogación de perjuicio patrimonial a través de la desviación del dinero, los efectos o la cosa mueble recibida en el marco de un vínculo de confianza especial, en términos tales que el perjuicio en cuestión ha de quedar determinado o bien por la frustración de la finalidad que justificaba la recepción de la cosa bajo el título respectivo, o bien por la falta de satisfacción del derecho personal correlativo a la obligación de entregarla o devolverla, según corresponda ${ }^{51}$.

En tal medida, la distracción indebida no puede ser entendida como un delito contra la propiedad, desde ya porque su configuración típica es enteramente compatible con que quien distrae indebidamente aquello

\footnotetext{
47 En sentido amplio, por ejercicio de un poder fáctico de disposición cabe entender tanto lo que cuenta como el ejercicio de la así llamada "facultad de disponer de la cosa", en cuanto "atributo del dominio", como el aprovechamiento ostensible de la cosa. En referencia a la tipificación de la (simple) apropiación de cosa ajena bajo el $\$ 246$ del CP alemán, Kindhäuser/Neumann/Paeffgen (2013), \$246, n. m. 5 ss., 11 ss. Véase Politoff (1957) 213 ss.; Sото (1994) 49 ss., aun cuando englobando ambos la "distracción” bajo el concepto más amplio de apropiación; véase supra, 2.1.2.

50 Politoff (1957) 219 ss.

51 Véase supra, 3.1.3.
} 
que ha recibido por un título indicativo de un vínculo de confianza especial sea o se haga dueño, en efecto, del objeto en definitiva distraído. Esto es de la mayor importancia práctica de cara a aquellos casos en los cuales lo recibido es dinero no especificado, precisamente porque entonces, encontrándose per se descartada la posibilidad de una apropiación a su respecto, subsistirá sin más la posibilidad de una distracción. Desde luego, ello no obsta a que también sea constructivamente posible una distracción indebida de una cosa recibida como especie o cuerpo cierto ${ }^{52}$.

Al igual que la apropiación, la distracción del objeto confiado puede asumir múltiples formas, el común denominador de las cuales estará constituido, en todo caso, por una aplicación desviada de lo que se ha recibido, lo cual quiere decir: una aplicación contraria a la finalidad para cuya realización el objeto en cuestión fuera confiado.

\section{4) LA CONGRUENCIA DE LA PROTECCIÓN DE LA PROPIEDAD Y EL PATRIMONIO}

\section{(4.1.) LA PROPIEDAD COMO POSICIÓN PATRIMONIAL}

Hasta aquí se ha procurado especificar la fisonomía precisa de los delitos de apropiación y distracción indebidas, entendidos como los respectivos géneros del quebrantamiento de dos normas de comportamiento reforzadas por una misma norma de sanción, formulada en el art. 470 No 1 del $\mathrm{CP}$, en términos de lo que ha sido caracterizado como una reconstrucción dualista del sentido y alcance de esta última disposición legal. Lo que resta por analizar es la razón susceptible de ser invocada para explicar la decisión legislativa así configurada. A este respecto, la particularidad de la versión de la estrategia de reconstrucción dualista aquí favorecida concierne a la

52 Interesantemente, en la jurisprudencia se conocen fallos condenatorios por distracción indebida pronunciados, entre otros, en contra de quien, como arrendatario y frente al correspondiente ejercicio del derecho legal de retención por parte del arrendador, hubo sido constituido como depositario de las cosas muebles de su propiedad ubicadas dentro del inmueble arrendado, habiendo posteriormente pignorado una parte de las especies en cuestión; véase Etcheberry, Alfredo (1968) El derecho penal en la jurisprudencia. Santiago: Editorial Jurídica de Chile, tomo III, pp. 40 ss., 43, 56 ss. Ello supone asumir que las cosas conservadas en depósito habrían sido "recibidas" en tal carácter por su dueño. Nótese, adicionalmente, que tratándose de cosas constitutivas del "simple menaje" de una casa-habitación, siendo ellas embargadas y quedando, empero, en poder del deudor, su "sustracción” por parte de este resulta punible como delito de alzamiento de bienes en depósito (o de "depositario alzado"), en conformidad con el inc. final del art. 444 del Código de Procedimiento Civil, que por vía de remisión hace aplicable el marco penal previsto en el art. 471 No 1 del CP (que tipifica, a su vez, el furtum possessionis). 
identificación del parentesco sistemático que ha de reconocerse entre uno y otro género delictivo, sobre la base de una correspondiente comprensión de la relación en que se encuentran la propiedad y el patrimonio qua respectivos objetos de protección de las dos normas de comportamiento precedentemente identificadas. Es desde este punto de vista que cabe hablar de una estrategia unificadoramente dualista, a saber, en razón de la unificación de la protección dispensada a la propiedad y al patrimonio que resulta de las premisas en las cuales esa misma estrategia se apoya.

Como es obvio, el esclarecimiento de la relación en que se encuentran los conceptos de propiedad y patrimonio, desde el punto de vista de la elaboración dogmática de la parte especial de algún determinado ordenamiento jurídico-penal, depende críticamente de qué se entienda por "propiedad" y "patrimonio". Tal como ya fuera sugerido, la cuestión tiende a quedar unilateralmente asociada a la definición del concepto de patrimonio, lo cual se explica por el hecho de que esta definición tiende a ser doctrinalmente mucho más controversial -0 , al menos, más controvertida- que la del concepto de propiedad ${ }^{53}$. Esto no obsta, sin embargo, a que sea precisamente en referencia a la pregunta por la congruencia o incongruencia entre la protección jurídicamente dispensada, y jurídicopenalmente reforzada, a la propiedad y el patrimonio que admiten ser contrapuestas las diferentes concepciones que se disputan la definición del concepto mismo de patrimonio ${ }^{54}$. Esto ha sido especialmente enfatizado por Kindhäuser, según quien el contraste entre la concepción económica, la concepción jurídico-económica y la concepción funcional del patrimonio puede justamente articularse desde el punto de vista de la pregunta de si, bajo cada una de ellas, la protección (jurídico-penalmente reforzada) de la propiedad y el patrimonio resulta congruente o incongruente, tanto en sentido material como en sentido formal ${ }^{55}$. Para simplificar la explicación, puede ser útil construir la comparación tomando la prohibición del hurto y la prohibición de la estafa como paradigmas de normas de comportamiento que respectivamente protegen la propiedad y el patrimonio.

53 Lo cual ciertamente no significa que la determinación del concepto de propiedad no esté acompañada de controversias. Considérese, a modo de simple contraste, lo sostenido en Mañalich (2009) 35 ss., 38 ss., y en Oliver, Guillermo (2013) Delitos contra la propiedad. Santiago: LegalPublishing/Thomson Reuters, pp. 67 ss., 77 ss., donde se afirma que, bajo el CP chileno, por "propietario" habría que entender no solo al dueño de una cosa en sentido jurídico-civil, sino asimismo al mero tenedor legitimado para detentar la cosa en cuestión.

54 En estos términos, una concepción del patrimonio especifica criterios para la aplicación del concepto (controvertido) de patrimonio; para una explicación ya canónica de la distinción entre un concepto y una o más concepciones rivales que lo especifican, véase Dworkin, Ronald (1986) Law's Empire. Cambridge (Mass.): Harvard University Press, pp. 70 ss. KindhäUSER (2002) 36 ss. 
Una incongruencia tanto material como formal entre la protección de la propiedad y la protección del patrimonio es lo que resulta de la adopción de la concepción puramente económica del patrimonio. La incongruencia en sentido material está determinada por el hecho de que, bajo esta concepción, una misma posición de una persona en relación con una cosa, consistente en el poder de disposición que aquella tiene sobre esta, puede resultar protegida bajo la prohibición del hurto y desprotegida bajo la prohibición de la estafa. Este será precisamente el caso si la cosa en cuestión carece de valor de mercado: la apropiación mediante sustracción por parte de P, siendo P una persona distinta del dueño, resultará prohibida sub specie hurto ${ }^{56}$, en circunstancias de que la obtención de la cosa, por parte de $\mathrm{P}$, en virtud de una disposición efectuada por el dueño (o por un tercero que actúe por cuenta de este) bajo un error resultante de un engaño, desplegado por $\mathrm{P}$, no resultaría prohibida sub specie estafa. Pues al carecer la cosa de valor de mercado, un partidario de la concepción económica del patrimonio tendría que negar que la disposición en cuestión, resultante en la obtención del poder de disposición sobre la cosa por parte de P, haya sido patrimonialmente perjudicial para el dueño y patrimonialmente ventajosa para P. Pero esta incongruencia material se ve acompañada de una incongruencia ya formal, consistente en una auténtica inconsistencia axiológica: puesto que la concepción económica no valida criterio de adscripción jurídica alguno que determine qué posiciones patrimoniales son atribuidas a una persona, la posesión "viciosa" (por clandestinidad) que el ladrón obtiene respecto de su botín tendría que entenderse como una posición que le está protegida bajo la prohibición de la estafa, a pesar de tratarse de una posición resultante de un quebrantamiento de la prohibición del hurto por su parte.

Frente a esto, el correctivo que lleva a transformar la concepción económica en una concepción jurídico-económica del patrimonio se traduce en una superación de la incongruencia formal. Pues la necesidad de que se satisfaga un criterio de adscripción jurídica de la correspondiente po-

56 Por supuesto, es posible concebir la defensa de una tesis según la cual hubiera que negar la protección de la propiedad sobre cosas carentes de valor de mercado a través de la prohibición del hurto. Lo que habría que notar, sin embargo, es que en tal caso, siendo indudable que hay propiedad (jurídicamente reconocida) sobre cosas carentes de valor de mercado, la prohibición del hurto ya no podría ser caracterizada como una norma que protege la propiedad ajena, sino más bien como una norma que protege el patrimonio ajeno, entendido este en el sentido de la concepción económica. Como es obvio, desde ese mismo punto de vista dejaría de tener sentido la pregunta por la congruencia o incongruencia entre la protección dispensada a la propiedad y la protección dispensada al patrimonio a propósito de la comparación de las finalidades de protección respectivamente atribuibles a la prohibición del hurto y a la prohibición de la estafa. 
sición para que esta pueda ser reconocida como integrando el patrimonio de una persona excluye que la posesión viciosa del ladrón sobre la cosa hurtada pueda ser entendida como una posición patrimonial protegida a su respecto. Pero la concepción jurídico-económica mantiene la incongruencia material ya tematizada, puesto que la propiedad sobre una cosa que carezca de valor de mercado no podrá encontrarse protegida bajo la prohibición de la estafa, por no tratarse en tal medida de una posición patrimonial, a pesar de que la misma sí resultará protegida bajo la prohibición del hurto. Y esto último es sumamente difícil de justificar: si el poder de disposición sobre una cosa, correspondiente al propietario de esta, se encuentra protegido -bajo la prohibición del hurto- frente a su (apropiación mediante) sustracción por parte de cualquiera otra persona, no hay razón sistemática alguna que justifique que ese mismo poder de disposición, correspondiente al propietario, no esté asimismo protegido -bajo la prohibición de la estafa- frente a su obtención resultante de una disposición condicionada mediante engaño ${ }^{57}$.

La concepción funcional del patrimonio, propuesta por Kindhäuser y aquí favorecida, hace posible arribar a una congruencia tanto formal como material ${ }^{58}$. En la medida en que bajo esta concepción el patrimonio debe ser entendido como "el poder de disposición de una persona sobre (el conjunto de) los bienes transferibles (pecuniariamente valorizables) que le están juridicamente adscritos" 59 , es claro que la propiedad sobre una cosa cuenta, ex definitione, como una posición patrimonial. Así, aquello que bajo la prohibición del hurto se encuentra protegido frente a su obtención, por parte de alguien distinto del dueño, resultante de una (apropiación mediante) sustracción, también se encuentra protegido frente a su obtención, por parte de alguien distinto del dueńo, resultante de una disposición condicionada mediante engaño.

En contra de esta concepción no cabría esgrimir la objeción de que, de lege lata, el derecho chileno cuantifica la gravedad de múltiples especies de hecho punible inequívocamente constitutivas de delitos contra el patrimonio en referencia a la valorización pecuniaria del perjuicio patrimonial irrogado. Pues con arreglo a la concepción funcional del patrimonio, este queda integrado por posiciones relativas a objetos (de la más diversa índole) susceptibles de valorización monetaria, sin que esto último pueda ser equiparado sin más a la determinación de su -solo eventual

Kindhäuser/Neumann/Paeffgen (2013) $\$ 263$, n.m. 29.

Así ya Mañalich (2009) 116 ss.

KindhäUser/Neumann/Paeffgen (2013) \$263, n.m. 35. 
y en todo caso volátil- valor de mercado ${ }^{60}$. En lo que aquí interesa, sin embargo, es todavía más importante reparar en que semejante cuantificación de la gravedad relativa del injusto del respectivo hecho punible, asimismo de lege lata, no es privativa de la tipificación de delitos contra el patrimonio, sino que también es reconocible en la tarifación penológica del hurto, que es justamente un paradigma de delito contra la propiedad. Esto último es enteramente consistente con que el menoscabo de la propiedad, que especifica el injusto propio del hurto, deba ser entendido $e o$ ipso como un menoscabo de significación patrimonial, precisamente por el hecho de que ese menoscabo incide en el poder de disposición, jurídicamente reconocido a una persona, sobre una cosa susceptible de ser valorizada en dinero. Y aquí no estaría de más notar que los criterios fijados en el art. 455 del $\mathrm{CP}^{61}$, para la valorización pecuniaria del monto de lo hurtado, no necesitan en modo alguno concebirse como orientados a la identificación del (solo eventual) valor de mercado de las cosas sustraídas.

\section{(4.2.) LA RELACIÓN SISTEMÁTICA ENTRE APROPIACIÓN INDEBIDA Y DISTRACCIÓN INDEBIDA}

La congruencia material y formal de la protección dispensada a la propiedad y el patrimonio, favorecida por la adopción de la concepción funcional del patrimonio, encuentra una confirmación definitiva, también de lege lata, en la tipificación de los delitos de apropiación indebida y distracción indebida de cosa confiada, plasmada en el art. 470 No 1 del $\mathrm{CP}$, tal como ello es hecho explícito a través de una reconstrucción dualista de esta última disposición legal. En estos términos, empero, lo que distingue a la presente versión de semejante estrategia dogmática consiste en que, complementada con la concepción funcional del patrimonio, la propuesta interpretativa así obtenida puede ser más precisamente caracterizada como una conducente a una reconstrucción unificadoramente dualista del sentido y alcance de la decisión de tipificación legislativa. Ello hace posible dar pleno sentido no solo a la existencia de presupuestos tí-

60 Por ello, no es admisible identificar sin más la noción de valor de mercado con la noción de "valor de cambio", como lo hace, sin embargo, Hernández (2009) 85 ss., en su defensa de la concepción económica del patrimonio. Pues el valor de cambio de una cosa consiste en el valor cuantificable que ella tiene en términos de alguna otra cosa, de modo tal que una cosa tiene valor de cambio cuando es posible obtener alguna otra cosa -valga la redundancia- a cambio de ella, lo cual es conceptualmente independiente de que esa cosa tenga asignado un precio que fije su correspondiente valor de mercado.

61 Que dispone: "Cuando del proceso no resulte probado el valor de la cosa substraida, ni pudiere estimarse por peritos u otro arbitrio legal, el tribunal hará su regulación prudencialmente”. 
picos comunes a uno y otro delito ${ }^{62}$, sino también al hecho mismo de su tipificación conjunta. Pues en términos de la solución aquí propuesta, el injusto propio del delito de apropiación indebida se corresponde, sistemáticamente, con una especificación del injusto del delito de distracción indebida. Pues la forma de comportamiento identificada con la distracción de una cosa confiada, consistente en desviar el objeto recibido de un modo que determine o bien la frustración de la finalidad para cuya consecución el mismo fuera recibido, o bien la imposibilidad del cumplimiento de la obligación de entregarlo o restituirlo, según corresponda, se verá realizada por todo comportamiento que al mismo tiempo sea constitutivo de una apropiación de cosa confiada ${ }^{63}$.

Esto último tiene una consecuencia de la mayor importancia: si la tipificación de la apropiación indebida se encuentra en relación de lex specialis frente a la tipificación de la distracción indebida, en el sentido de que el primer tipo se encuentra en una relación lógico-semántica de subordinación (o inclusión) respecto del segundo ${ }^{64}$, entonces es claro que la imputación de un comportamiento que satisfaga ambas descripciones en referencia a un mismo objeto -lo cual será necesariamente el caso cada vez que se satisfaga la primera de esas dos descripciones- jamás podrá dar lugar una doble condena. Pues en tal situación la condena por apropiación indebida habrá de desplazar, por exigencia del principio ne bis in idem, la condena por distracción indebida, en atención al carácter "aparente" del concurso así constituido entre uno y otro delito, fundando en el criterio de la especialidad ${ }^{65}$.

\section{BIBLIOGRAFÍA}

Abeliuk, René (1993) Las Obligaciones. 3a edición. Santiago: Editorial Jurídica de Chile, tomo I, 474 pp.

Bascuñán, Antonio (2004) "Delitos contra intereses instrumentales". Revista de Derecho de la Universidad Adolfo Ibáñez, No 1, pp. 291-345. Binding, Karl (1902) Lehrbuch des Deutschen Strafrechts. Besonderer Teil. $2^{a}$ edición. Léipzig: Wilhelm Engelmann, tomo I, 545 pp.

\footnotetext{
62 Supra, 3.1.

63 Véase supra, 3.3.

64 Latamente al respecto Mañalich, Juan Pablo (2016) "El concurso aparente como herramienta de cuantificación penológica de hechos punibles”. En Cárdenas, Claudia y Ferdman, Jorge (coordinadores): El Derecho Penal como Teoría y como Práctica. Libro en Homenaje a Alfredo Etcheberry Orthusteguy. Santiago: Thomson Reuters/La Ley, pp. 516 ss. 
Binding, Karl (1916) Die Normen und ibre Übertretung II. 2a edición. Léipzig: Felix Meiner, 1273 pp.

Binding, Karl (1922) Die Normen und ihre Übertretung I. 4a edición. Léipzig: Felix Meiner, tomo I, 508 pp.

Carrara, Francesco (1966) Programa de Derecho Criminal. Parte Especial. $2^{a}$ edición. Bogotá: Temis, vol. IV, 549 pp.

Cuello Calón, Eugenio (1957) Derecho Penal. 10a edición. Barcelona: Bosch, tomo II, 1003 pp.

De la Fuente, Felipe (2005) "Delitos contra bienes instrumentales". Revista de Derecho de la Universidad Adolfo Ibánez, No 2, pp. 557-618.

Dworkin, Ronald (1986) Law's Empire. Cambridge (Mass.): Harvard University Press, $470 \mathrm{pp}$.

Etcheberry, Alfredo (1968) El derecho penal en la jurisprudencia. Santiago: Editorial Jurídica de Chile, tomo III, $472 \mathrm{pp}$.

Etcheberry, Alfredo (1998) Derecho Penal. Parte Especial. $3^{\text {a }}$ edición. Santiago: Editorial Jurídica de Chile, tomo III, 490 pp.

Fueyo, Fernando (1958) Derecho Civil IV. De las obligaciones. Valparaíso: Imprenta y Litografía Universo, vol. 1, 414 pp.

Garrido, Mario (2008) Derecho Penal. Parte Especial. Tomo IV. 4a edición. Santiago: Editorial Jurídica de Chile, 459 pp.

Hernández, Héctor (2005) "La administración desleal en el derecho penal chileno". Revista de Derecho de la Pontificia Universidad Católica de Valparaiso, vol. XXVI, pp. 201-258.

Hernández, Héctor (2009) "Frustración de fines y perjuicio patrimonial en el derecho penal chileno". Derecho Penal Contemporáneo, No 29, pp. 57-91.

Kindhäuser, Urs (2002) Estudios de derecho penal patrimonial. Lima: Grijley, 194 pp.

KindhäUser, Urs (2011) "Concepto de patrimonio y perjuicio patrimonial. Sobre los defectos congénitos de la doctrina económica del perjuicio en el derecho penal". Anuario de Derecho Penal Económico, vol. 1, pp. 51-58.

Kindhäuser, Urs; Neumann, Ulfrid; Paeffgen, Hans-Ullrich (2013) Nomos Kommentar. Strafgesetzbuch. $4^{a}$ Edición. Baden-Baden: Nomos, tomo III, 2173 pp.

Labatut, Gustavo (2005) Derecho Penal. 7a edición. Santiago: Editorial Jurídica de Chile, tomo II, 263 pp.

Larenz, Karl (1987) Lehrbuch des Schuldrechts. 14a edición. Múnich: Beck, tomo I, 668 pp.

Mañalich, Juan Pablo (2009). Autotutela del acreedor y protección penal del deudor. Santiago: Ediciones Jurídicas de Santiago, 134 pp.

Mañalich, Juan Pablo (2011) "El delito como injusto culpable". Revista de Derecho UACh, vol. 24, No 1, pp. 87-115. 
Mañalich, Juan Pablo (2014) "La violación como delito contra la indemnidad sexual bajo el derecho penal chileno. Una reconstrucción desde la teoría de las normas". Ius et Praxis, año 20, $\mathrm{N}^{\circ} 2$, pp. 21-70.

Mañalich, Juan Pablo (2016) "El concurso aparente como herramienta de cuantificación penológica de hechos punibles". En Cárdenas, Claudia y Ferdman, Jorge (coordinadores): El Derecho Penal como Teoria y como Práctica. Libro en Homenaje a Alfredo Etcheberry Orthusteguy. Santiago: Thomson Reuters/La Ley, pp. 501-547.

Oliver, Guillermo (2013) Delitos contra la propiedad. Santiago: Legal Publishing/Thomson Reuters, $591 \mathrm{pp}$.

Pardow, Diego (2006) "Potestades de administración y deberes fiduciarios. Una aproximación analítica a los deberes asociados a la administración de un patrimonio ajeno”. En Corral, Hernán y Rodríguez, María Sara (coordinadores): Estudios de Derecho Civil II. Santiago: LexisNexis, pp 89-112.

Politoff, Sergio (1957) El delito de Apropiación Indebida. Santiago: Editorial Nascimento, 243 pp.

Politoff, Sergio; Matus Jean; Ramírez, María (2004) Lecciones de Derecho Penal Chileno. Parte Especial. 2a edición. Santiago: Editorial Jurídica de Chile, 689 pp.

Sandoval, Ricardo (2015) Derecho Comercial. Santiago: Editorial Jurídica de Chile, tomo II, 328 pp.

Schlack, Andrés (2008) "El concepto de patrimonio y su contenido en el delito de estafa". Revista Chilena de Derecho, vol. 35, $\mathrm{N}^{\circ} 2$, pp. 261-292.

Soler, Sebastián (1987) Derecho Penal Argentino. 4a edición. Tea: Buenos Aires, tomo IV, $735 \mathrm{pp}$.

Soto, Miguel (1994) Apropiación indebida. Santiago: ConoSur, 100 pp.

Tomasello, Leslie (1994) Las obligaciones de dinero: régimen de reajuste e intereses. 2a edición. Valparaíso: Edeval, 189 pp.

\section{JURISPRUDENCIA CITADA}

Corte de Apelaciones de Valparaíso. 10 de octubre del 2013. Rol N ${ }^{\circ}$ 1263-13. "Ministerio Público con Escobar Donoso, Germán A.”.

Corte de Apelaciones de Concepción. 23 de julio del 2010. Rol N²732010. "Ministerio Público con Ulloa Pino, Leonardo Alex".

Corte de Apelaciones de San Miguel. 30 de abril del 2009. Rol No 1102009. "Hernández Arata, César Marcelo con Contreras Castillo, Ana María". 